\title{
Parent-Child Attachment and Romantic Relationship among Young Adults in Malaysia
}

\section{Fatahyah Yahya ${ }^{\text {a }}$, Sharon Wilson ${ }^{\mathrm{a}}$, Antigonos Sochos ${ }^{\mathrm{a}}$, Ahmad Tarmizi Talib ${ }^{\mathrm{a}}$, Sarjit Singh Darshan Singh ${ }^{a}$, Muhammad Jazlan Ahmad Khiria , Aqeel Khan ${ }^{\text {b }}$}

\author{
${ }^{\text {a} F a c u l t y ~ o f ~ C o g n i t i v e ~ S c i e n c e s ~ a n d ~ H u m a n ~ D e v e l o p m e n t, ~ U n i v e r s i t i ~ M a l a y s i a ~ S a r a w a k, ~ K o t a ~ S a m a r a h a n, ~}$ \\ Sarawak, Malaysia. \\ ${ }^{\mathrm{b}}$ Faculty of Social Sciences \& Humanities, Universiti Teknologi Malaysia (UTM), Skudai, Johor, Malaysia.
}

Article History: Received: 11 January 2021; Accepted: 27 February 2021; Published online: 5 April 2021

\begin{abstract}
The aim of this research was to examine the relationship between Parent- Child Attachment on Romantic Relationship among Young Adults in Malaysia. In the present study, researcher established the correlation between the two variables which are Parent-child attachment and romantic relationship. Total of 100 participants (36= Male; 64: Female) participated in this study. Two (2) instruments have been used to measure the variables; Armsden and Greenberg's Inventory of Parent and Peer Attachment (IPPA) and Experiences in Close Relationships scale (ECR). Results indicated that there was a positive moderate significant relationship between parent child attachment and romantic relationship among young adults in Malaysia $(\mathrm{r}=.322, \mathrm{p}<0.01)$. As a recommendation, a semi-structured interview can be administered to investigate the nature of attachment relationships in adult partnerships.
\end{abstract}

Keywords: Attachment, Parent, Romantic Relationships, Young Adults.

\section{Background of the Study}

There are quite a number of research that has been conducted to investigate the effect of how the level of parentchild attachment security affects the level of romantic responsiveness and co-operation between romantic partners or couples (Millings, Walsh, Hepper, \& O’Brien, 2013). According to Department of Statistics Malaysia (2019), it has been reported that the number of divorces has increased 0.1 percent from 50,314 in 2017 to 50,356 in 2018. Some news from Malaysia Kini (2019) has reported that a total of 4,963 cases of domestic abuse that has been reported in 2018 and the statistic showed by Women's Aid Organisation (2020) reported that most of the domestic violence cases are happened to be among young adult aged 26 to 35 . These data have given insight for the researcher to focus on the relationship of Parent- Child Attachment on Romantic Relationship among Young Adults in Malaysia.

According to the theory of attachment, parent child attachment pattern is generally mirrored and reflected in three representations; secure insecure avoidant (Type A); secure (Type B); and, insecure anxiety (Type C) (Ainsworth, 1978). Avoidant of attachments refers to the suppression and the denial of the need of attachment. Anxiety of attachments refers to hyper-activation of attachment need as reflected in intense possessiveness and fear of being abandoned (Mikulincer \& Shaver, 2007).

Attachment security refers to the sense of security being developed because of the availability and responsiveness of primary caregivers towards a child's different phases of growth and need of attachment. Studies further show that avoidant and anxiety of attachment are related with authoritarian and permissive parenting styles and have negatively affected individual's ability to respond intimately to romantic partners. Conversely, it is also identified that people with attachment security that is high because of authoritative parenting styles make the most responsive and supportive romantic partners. Therefore, the parallel pattern of parenting style and attachment orientations; whether authoritarian/avoidant; authoritative/secure; or, permissive/ ambivalent; should serve as a mechanism to examine the link between attachment orientation and romantic attachment between couples (Hong \& Park, 2012). This research paper aims to mediate the significant link between the two variables, For instance, parent-child attachment and romantic attachment, among the Malaysian couples in contextual reality.

\section{Statement of Problem}

Attachment scholars have focused on results of attachment between children and their caregivers. Nevertheless, there is a lack of studies examining the relationship of parent-child attachment on later romantic relationships among young adults in Malaysia. Study of attachment between parent and child has been crucial especially in Malaysian context and the lack of findings regarding the parent child attachment and how it influence romantic relationships among young adults somehow have contribute to a few common issues in Malaysia such as the increase rate of divorces and domestic violence; low life satisfaction among married couples and relationship partners; poor work performances; and poor academic achievements. According to Creasy and Ladd (2004), young 
adult with attachment that is secured shows better in managing conflict in their romantic relationships or critical thinking abilities than young adult with attachment that was insecure with their parents. In contrast with a research by Lopez, Melendez and Rice (2000), there are no relationship between the attachment between parents and young adults towards future romantic relationship as the findings of the study showed that young adults with divorced parents have no significant relationships with those who has parents' care and attachment. These two studies have served a gap in which current study need to be conducted in Malaysia population.

\section{Parent Child Attachment}

Attachment theory proposes the attachment or connection between a child and their parents which fills in as a reason for different relationships (Bowlby, 1969). Initial attachment forms the base of self-esteem and relationships. According to Waters et al (2003), The attachment between the parent and the child has significant influence on a child's development along the time as it associates with the peers, educator, and their romantic partner attachment in their later life. Parental attachment in young adults works in similar ways as it did in early adolescence, serving as foundation for investigation and the enhancement of the child's reasoning, emotional capabilities and social (Allen et al., 2003). According to Parker et al. (2009), the relationship in mother-child and father-child attachment plays an influential role in the development of the feeling of self-assurance and self-esteem of their child which might also be somewhat responsible for later romantic relationship.

According to a previous study by Brown et al (2007), which aimed to study the child rearing indicators of attachment security between father and the child in the child's early years. This study only focuses on father-child attachment instead of both parents. Results of Brown et al (2007) study shown that several components of a fathers in the parenting quality directed the relationship between involvement of the father, in its unique sense of contentfree, and father-child attachment. In particular, when the parenting of a father was less adaptive which will result in lower levels of attachment security, however when fathers involved with great parenting behaviour, the involvement of a father role was commonly unrelated to attachment security (Brown et al., 2007). For instance, fathers' involvement in taking care of the child and more time spending in play on non-workdays happens to induce greater attachment security, with somewhat stronger effects in bonding together to play. On workdays, more time spent in taking care of the child and minimum time in play predicts attachment security that is higher levels of (Brown et al., 2007).

In contrast to Cooke (2019) research which aimed to study the strength of the relationship of attachment with emotional regulation and the children's experience and that is under 18 years old. Researchers analysed parentchild relationship instead of peer attachment, as parents are viewed as the key operators of children's socialization of feeling and furthermore fill in as the figures of the essential attachment for children well into teenage years (Rosenthal \& Kobak, 2010). The findings of Cooke et al. (2019) reported children that is more securely attached experienced less comprehensive negative effect and more comprehensive positive effect, expressed less negative effect that is elicited, the child was more matured and able to control feelings, and frequently utilized intellectual and social help adapting systems. Children that is avoidant of attachment experienced less comprehensive positive effect, were less able to control and manage their feelings, and were less inclined to utilize cognitive or social help adapting techniques Cooke et al. (2019). Conversely, children that is more conflictedly attached, experienced increasingly global and progressively evoked negative effect, and were less able to manage feelings.

According to a study done by Cruz (2013), researcher hypothesized that there is no significant relationship between parent-child attachment and later satisfaction in personal relationship. The result of Cruz (2013) pointed that the attachment between child and their parent is highly correlated with later satisfaction of personal relationship: There is a significant positive association between the care of the mother and emphatic compromise and communication, while there is an immense antagonistic relationship among overprotected mother and father as well as autonomy and closeness, correspondingly. The literature demonstrates that authoritative or minding parenting style (that highlights on attachments between parents and children that is positive) that implied are bound to be secure in their personal relationship of their child. In contrast, relationship security is not obvious among children who gotten a lenient child rearing style (Parker et al., 2009). Besides, early relationships of between the children and the parents play an important role in present patterns of relationship and autonomy. Men who experienced attachment that is positive to their mothers or female caregivers are more likely to experience positive attachment to their wife, girlfriend or partners (Cruz, 2013). Similarly, women in intimate relationships that is secure perceive themselves as having received more acceptance or care from their fathers or male caregivers in childhood than those in meaningless or enmeshed relationships (Parker et al., 2009).

\section{Romantic Relationship Among Young Adults}


Research that has been carried out in the United States have demonstrated that from early to late adolescence the involvement in romantic relationships roughly doubles, from $30 \%-36 \%$ in early adolescence to $67 \%-72 \%$ in late adolescence which is the young adults (Overbeek et al., 2003). Furthermore, involvement in romantic relationships provide the perspective where issues of sexuality and intimacy are addressed, of fundamental concern to the adolescents' identity development (Overbeek et al., 2003). According to Avila, Cabral ad Matos (2012), researchers pointed out that young adults that are not able to build up and sustain romantic relationships might lead to loneliness, which can result in depressive dispositions and feelings of low self-confidence.

Young adults who can effectively set up and keep up positive romantic relationships will in general be more satisfied with their lives and better balanced well into later life (Adamczyk and Segrin, 2016). According to Finecham and Cui (2011), a few previous research regularly conceptualized romantic relationship quality during early adulthood as a comprehensive construct of a solitary (Dush \& Amato, 2005). Nevertheless, analysing forerunners and the process of development of specific parts of the functioning of young adult romantic relationship, for example, relationship related critical thinking abilities, love, and conflict, can give significant and more specific information about the development of both relationship-related formative results and the components that influence these dimensions (Dush \& Amato, 2005).

A previous research by Connolly and Melsacc (2011) which study the romantic relationship among adolescence and the result proposed that associations of the young with their parents and peers can affect their quality and involvement of their romantic relationship. For instance, it has been demonstrated that young adults that experience high quality associations with their parents and peers are bound to have a romantic relationship that is higher quality (Roisman et al., 2009). Connolly and Melsacc (2011) pointed out that regardless of whether early romantic relationships are less obvious and intimate than later ones, they are significant to given the indication that early association in romantic relationship is associated to less adjustment, and early encounters in romantic relationships may establish a basis for romantic relationships that develop later in adulthood.

\section{Parent Child Attachment on Romantic Relationship among Young Adults}

The observation of parents, and relationships with parents could be a factor for relationships later on. The family "context" in most cases will have a role in the aptitudes that an individual will have in a romantic relationship (Hare, 2009). The development of those romantic relationships, and any closeness that they build in those relationships, is seen to be impacted by their parents, explicitly the way in which the parents brought up their children, and the level of attachment (Nosko, 2011). According to Nosko (2011), a person who has a working model that is secure with a parent is increasingly disposed to have an attachment that is secure with an intimate or romantic partner. However, a person who has an anxiously attached relationship with parents will in general have an attachment that is insecure with their romantic partner, representing that they might be wary or anxious about the commitment of their partner, and the desire to be closer to that individual (Twedt, 2013).

According to Blake (2006), secure adults are seen to have had their needs met, both sensitively and regularly in their earlier years. This allows them to have no trust issue with other people in their life, and to be able to be open with others. In contrast with insecure adults find it more challenging to allow others to get close to them since they do not expect another person to accept them. They feel they will be rejected. They may also demand the other person to be very close to them because their parents have been "unavailable".

According to a previous research by Del Toro (2012) which aimed to study the importance of relationship between the parent and the child and in what way the child rearing styles used, and parent-child attachment associated with future reports of anxiety in romantic relationship. By using multiple regression analysis, Del Toro (2012) finding showed that authoritative child rearing styles and a parent-child attachment that is secure represented an absence of attachment anxiety, indicating that participants who reported a romantic relationship that is secure tend to have been raised by parents who used an authoritative child rearing style and furthermore encountered a parent-child attachment that is secure when growing up. Besides that, result of the study also suggested when children have a healthy relationship with their parents, they are bound to have romantic relationship patterns that is healthy in future romantic relationships (Del Toro, 2012).

In contrast with research by Kochendorfer and Kerns (2017) which intended to study how attachment and friendship quality at age 10 years foresee the engagement and quality of romantic relationship at ages 12 and 15 years. Different from Del Toro (2012) study, Kochendorfer and Kerns (2017) study has another element, which is friendship quality that my influence romantic relationship beside parent-child attachment. Researchers have used longitudinal design and their results suggested that mother-child attachment security anticipated engagement in a romantic relationship, while the quality of friendship anticipated both romantic engagement and quality of romantic 
relationship (Kochendorfer and Kerns, 2017). Even though mother-child attachment anticipated the involvement of romantic relationship, surprisingly it was not predictive of the quality of romantic relationship at ages 12 or 15 years. With that, researchers clarified the finding where their research emphasized on early romantic relationships, and it might be that attachment is not related with quality of romantic relationship until late adolescence when romantic relationships become more intimate (Kochendorfer and Kerns, 2017).

Another past research by Dinero (2011) which stated one of the objectives of the research is to study the influence of the family quality associations during adolescence to later romantic attachment styles and the quality of romantic contacts in adulthood. Researcher run correlation between attachment with parents and romantic partners and the results of study revealed that correlation does not halt at young adulthood either. It has been discovered that marital satisfaction could be associated with the relationship that the individual holds with a parent (Dinero, 2011). marital satisfaction could be associated with the relationship that the individual holds with a parent.

\section{Theoretical Framework}

Drawing on ethological hypothesis, Bowlby suggested that these relationships practices, for instance, crying and seeing, were adaptive responses to separation from an important figure of attachment (Fraley \& Shaver, 2016). Someone who offers support, assurance, and care. Since new-born children, as other mammalian babies, cannot feed or protect themselves, they are reliant upon the reflection and assurance of "older and wiser" adults. Bowlby opposed that, through the span of the history of transformation, new-born children who had the choice to keep up vicinity to a figure of attachment by means of behaviours of attachment would be bound to survive due to a reformative age (Ainsworth \& Bell, 1970). As designated by Bowlby (1988), an inspiring framework, what he socalled the attachment social framework, was progressively "designed" by distinctive option to regulate closeness to a figure of attachment.

The framework of behaviour of attachment is a significant idea in theory of attachment since it gives the conceptual relationship between models of ethological of development of human and current theories on regulation of emotion and attributes Bowlby (1988). According to Bowlby (1988), the system of attachment basically "asks" the accompanying basic questions: Is the figure of attachment close by, available, and mindful? If the kid sees the response to this inquiry to be "yes," the individual in question feels cherished, secure, and loved, and, naturally, is perhaps going to explore their environment, like make friends with others (Ainsworth \& Bell, 1970).

Assuming, nonetheless, the kid sees the reply to this question to be "no," the kid experiences anxiety and, usually, is probably going to display behaviours of attachment ranging from basic visual looking on the low outrageous to dynamic after and vocal signalling on the other. These behaviours continue until either the kid can reinstate a desirable degree of physical or mental proximity to the figure of attachment, or until the kid "wears down," as may occur with regards to a drawn-out separation or loss. In such cases, Bowlby believed that children experienced substantial sadness and depression.

Although Bowlby was principally centred around understanding the knowledge of parent-child relationship, he believed that attachment characterized experience of human from "the cradle to the grave" (Fraley, 2018). It was not until the mid-1980's, anyhow, that researchers started to focus on the probability that processes of attachment may happen in adulthood. Hazan and Shaver (1987) were two of the primary researchers to study Bowlby's ideas with regards to romantic relationships. The expressive bond that develops between romantic adults that are in intimate relationship is mostly an element of the equivalent system of motivation (Hazan \& Shaver, 1987).

The framework of attachment behaviour that suggest ascending to the passionate bond among new-born children and their caregivers' figures. Hazan and Shaver (1987) observed that the association between babies and their parents and the association between grown-up romantic partners share the following structures; both have a sense of security when the other is close by and responsive, both share right up front, close, intimate substantial contact, both feel insecure when the other is difficult to reach, both offer disclosures with each other and show a common interest and distraction with each other and last but not least, both take part in "infant talk". Based on these parallels, Hazan and Shaver (1987) opposed that adult romantic relationships, like baby and parental figure associations, are attachments, and that romantic love is a property of the attachment social framework, just as the persuasive frameworks that offer ascent to providing care and sexuality (Fraley, 2018).

\section{Methodology}




\subsection{Research Design}

The present research study is a quantitative research and using correlational research design to access the relationship between Parent- Child Attachment on Romantic Relationship among Young Adults in Malaysia and using multiple regression to access the influence of Parent- Child Attachment on Romantic Relationship among Young Adults in Malaysia. Correlation analysis helps researcher to measure the closeness of the associations between the variables (Sharma, 2005). Therefore, researcher established the correlation between the two variables which are Parent-child attachment and romantic relationship. In the current study, researcher characterized Parentchild attachment as an independent variable whereas romantic relationships as dependent variable. Parent-child attachment will be measured using Armsden and Greenberg's Inventory of Parent and Peer Attachment (Armsden \& Greenberg, 1987). On the other hand, romantic relationships among young adult were measured using Experiences in Close Relationships scale (ECR; Fraley, Waller, and Brennan, 2000).

\subsection{Population and Sampling}

The sample of this study was recruited from young adults in Malaysia as the focus of this study is to study the influence of Parent- Child Attachment on Romantic Relationship among Young Adults in Malaysia population. 100 participants were recruited through simple random sampling. By using a simple random sampling method, researcher collected the data from participants that are willing to be studied across gender, age (18- 35 years old), occupation and cultural background which participants were given sets of questionnaires and relevant forms and questionnaires once they agreed to be part of this research study.

\subsection{Demographic Variables of the Participants}

\section{Demographic Data}

Table 1. The Demographic Variables of the Participants

\begin{tabular}{|c|c|c|c|}
\hline Variables & $\ldots$ & Frequency & Percentage $(\%)$ \\
\hline \multirow[t]{3}{*}{ Gender } & Male & 36 & 36 \\
\hline & Female & 64 & 64 \\
\hline & Total & 100 & 100 \\
\hline \multirow[t]{5}{*}{ Age } & $18-21$ & 19 & 19 \\
\hline & $22-25$ & 50 & 50 \\
\hline & $26-29$ & 14 & 14 \\
\hline & $30-35$ & 17 & 17 \\
\hline & Total & 100 & 100 \\
\hline \multirow[t]{5}{*}{ Ethnicity } & Malay & 26 & 26 \\
\hline & Chinese & 23 & 23 \\
\hline & Iban & 33 & 33 \\
\hline & Others & 12 & 12 \\
\hline & Total & 100 & 100 \\
\hline \multirow[t]{4}{*}{ Occupation } & Student & 50 & 50 \\
\hline & Employed & 34 & 34 \\
\hline & Unemployed & 16 & 16 \\
\hline & Total & 100 & 100 \\
\hline \multirow[t]{5}{*}{ Marital Status } & Single & 37 & 37 \\
\hline & In A Relationship & 49 & 49 \\
\hline & Married & 13 & 13 \\
\hline & Divorced & 1 & 1 \\
\hline & Total & 100 & 100 \\
\hline
\end{tabular}

There were total of 100 participants in this research where 36 are males and 64 are females. As this study emphasized more on young adults, participants age ranged from 18 to 35 participated in this study, grouping the ages was done to analyse the age differences where there are $19 \%$ of respondents aged range from 18 to 21 years old, $50 \%$ of 22 to 25 years old, $14 \%$ of 26 to 29 years old, and $17 \%$ of the respondents are 30 to 35 years old. From the descriptive statistics, it has shown that the majority respondents are aged ranged between 22 to 25 years old. 
According to the table, there are $50(50 \%)$ out of 100 respondents were students. $34(34 \%)$ are employed and the remaining $16(16 \%)$ are unemployed. As for the marital status, 37 of the respondents are single, 49 are in a relationship, 13 are married and 1 of the respondents divorced.

Table 2. The Mean and Standard Deviations of the Variables

\begin{tabular}{llc}
\hline \multicolumn{1}{c}{ Variables } & Means & SD \\
\hline Gender & 1.64 & 0.482 \\
Age & 25.06 & 4.438 \\
Ethnicity & 2.43 & 1.225 \\
Education Level & 4.61 & 0.931 \\
Employment Status & 1.85 & 1.077 \\
\hline
\end{tabular}

$S D=$ Standard Deviation

Based on table, it has shown that the mean for gender is 1.64 , whereas the SD is 0.482 . The mean and SD for age of the participants in this study is 25.06 and 4.438. The Ethnicity of the participants in this study scored 2.43 for mean and 1.225 for SD. It has shown that the mean for education level of the participants in this study is 4.61, whereas the SD is 0.931. The mean and SD for employment status of the participants is 1.85 and 1.077.

\subsection{Instrumentations}

Demographic information- Participants were asked to fill their demographic information in form that is attached with the other questionnaires. Demographic information such as, age, race, gender, and occupation will be asked in the form.

Armsden and Greenberg's Inventory of Parent and Peer Attachment (IPPA; Armsden \& Greenberg, 1987)Participants were asked to complete the 28 items inventory of parent and peer attachment which measures the attachment between the participants and their parents. The IPPA was established to measure how secure the level of attachment is between the parents and their children which consists of three subscales; trust (e.g., "My parents respect my feelings"), communication (e.g., "I tell my parents about my problems and troubles) and alienation (e.g., "My parents expect too much from me") between the parents and their children. This questionnaire will be responded using 5- point Likert scale from 1 (Almost Never or Never True) to 5 (Almost Always or Always True). The higher the score indicates there is a higher level of attachment. However, there are some reverse items which mean that the lower the score, the more the individual is attached to his or her parents, (e.g., "I get upset easily around my parents").

Experiences in Close Relationships scale (ECR-R; Fraley, Waller, and Brennan, 2000)- ECR is 36 items questionnaire which measured the levels of anxiety and/or avoidance which are experienced by individuals in a relationship. ECR was established to measure the attachment which includes anxiety or avoidant between the individual and their romantic partner. There are two subscales in ECR; attachment anxiety (e.g., "I'm afraid that I will lose my partner's love") and attachment avoidance (e.g., "I feel comfortable sharing my private thoughts and feelings"). This questionnaire is rated on a 5- point Likert scale from 1 (Strongly Disagree) to 5 (Strongly Agree), the higher the score indicates a higher pervasiveness of attachment anxiety or attachment avoidance.

\subsection{Pilot Study}

Pilot study was done to confirm the reliability and validity of the scale and items contained in the questionnaire form (Kronsnick,2018). Pilot research is also important to ensure weaknesses particularly in research questionnaires for example like grammatical usage and respondents' understanding and interpretation can be further improved to maintain consistency in the study before these instruments are used in the actual study. 
Fatahyah Yahya ${ }^{a}$, Sharon Wilson ${ }^{\mathrm{a}}$, Antigonos Sochos ${ }^{\mathrm{a}}$, Ahmad Tarmizi Talib ${ }^{\mathrm{a}}$, Sarjit Singh Darshan Singh ${ }^{\mathrm{a}}$, Muhammad Jazlan Ahmad Khiri, Aqeel Khan ${ }^{\mathrm{b}}$

\section{Pilot Study Test Results}

Table 3. Pilot Study Test Results

\begin{tabular}{ll}
\hline \multicolumn{1}{c}{ Variables } & Cronbach's Alpha Value \\
\hline A. Inventory of Parent and Peer Attachment (IPPA) (36 items) & .880 \\
B. Experiences in Close Relationships scale (ECR) (50 items) & .735 \\
Accumulate score reliability index $A-B^{*}(86$ items) & .879 \\
\hline
\end{tabular}

\section{The Results of Reliability Index}

Table 4. The Results of Reliability Index

\begin{tabular}{ll}
\multicolumn{1}{c}{ Variables } & Cronbach's Alpha Value \\
\hline A. Inventory of Parent and Peer Attachment (IPPA) & $.853(36$ items) \\
B. Experiences in Close Relationships scale (ECR) & $.763(50$ items) \\
Accumulate score reliability index A-B & $.850(86$ items) \\
\hline
\end{tabular}

Based on the results of the analysis of the reliability of the instruments involving two major instruments which are Inventory of Parent and Peer Attachment (IPPA) and Experiences in Close Relationships scale (ECR), there was a significant decrease in Cronbach Alpha results from $\alpha=.879$ to. 85 and followed by $\alpha=.88$ (36 items) to $\alpha=.853$ for IPPA, $\alpha=.735$ for ECR instrument has significantly increased to.76. In overall, the instruments used in this study have high reliability through item analysis.

\subsection{Data Collection and Analysis}

As mentioned previously, the participants were recruited through simple random sampling. Researcher collected the data from participants who are willing to be studied. Individuals who agreed to participate will be given a set of questionnaires attached with relevant details and forms such as informed consent, information sheet etc.

The collected data was analysed using Statistical Package of Social Science (SPSS). It was very important for the researcher to determine the internal consistency or the average correlations of every item in the questionnaires to measure the reliability. Thus, this study has been conducted and SPSS has been used to test the Cronbach's Alpha that measures internal consistency (Field, 2009). Pearson Correlation was used as the statistical techniques to analyse the data which was to determine the relationship between Parent- Child Attachment and Romantic Relationship among young adults in Malaysia. Chok (2010) described the Pearson Correlation is to determine the strength of the linear relationship between normally distributed variables. A few descriptive statistics was used to determine the mean and the standard deviation of the data (Ghaemi \& Yazdanpanah, 2014).

\section{Results}

\subsection{Descriptive Statistic}

Table 5. Descriptive Statistic for Parent- Child Attachment and Romantic Relationship

\begin{tabular}{ccc}
\hline Variables & Means & SD \\
\hline A. Inventory of Parent and Peer Attachment (IPPA) & 111.77 & 16.85 \\
B. Experiences in Close Relationships scale (ECR) & 159.02 & 16.94 \\
\hline
\end{tabular}

Based on Table 4.1, it has shown that the mean for Inventory of Parent and Peer Attachment (IPPA) is 111.77, and the SD is 16.85. The mean for Experiences in Close Relationships scale (ECR) is 159.02 and the SD is 16.94

\section{Pearson Correlation between Parent Child Attachment and Romantic Relationship}

Table 6. Pearson Correlation between Parent Child Attachment and Romantic Relationship

\begin{tabular}{lll}
\hline \multicolumn{1}{c}{ Relationship } & Correlation (r) & $\boldsymbol{p}$ \\
\hline $\begin{array}{l}\text { Parent Child Attachment } \\
\text { Romantic Relationship }\end{array}$ & $.322^{* *}$ & 0.001 \\
& &
\end{tabular}

** Significant at 0.01 
Based on the findings of the analysis of Table 6, there was a positive moderate significant relationship between parent child attachment and romantic relationship among young adults in Malaysia $(r=.322, p<0.01)$. It can be inferred that when children have secure or healthy relationship with their parents, it is most likely that they will experience secure or healthy romantic relationship when they are young adults. In other words, young adults that experience high quality associations with their parents are bound to have a romantic relationship that is higher quality (Roisman et al., 2009). This finding is consistent with a few previous researches where young adult with attachment that is secured shows better in managing conflict in their romantic relationships or critical thinking abilities than young adult with attachment that was insecure with their parents (Creasy and Ladd, 2004).

\section{Discussion, Implications and Recommendations \& Conclusion}

The development of romantic relationships has long been related with the relationship between parents and their children and the way in which these children have been brought up. Although many people begin to form intimate romantic relationships in their early adulthood, most research proposes that the development of romantic intimacy personalities and qualities begins in early childhood.

The key findings of this research shown there was a positive moderate significant relationship between parent child attachment and Romantic relationship among young adults in Malaysia. This result means that when a child has a secure attachment with his or her parents, the child will have a secure romantic relationship with his or her partner in the future. According to Black and Schutte (2006), individuals who had progressively positive and loving relationships and attachments with their mothers were more trusting and were bound to look for comfort from their romantic partners during difficult times and to open up to them. Likewise, individuals who had progressively positive and cherishing relationships and attachments with their fathers were bound to look for comfort from their romantic partners and were happier to depend on their partners. Apart from that, based on the previous research the quality and type of attachment children have with their parents or caregivers has been found to strongly propose the future quality of attachment in romantic relationships that child experiences as an adult (Mikulincer \& Shaver, 2009). The effect of parent-child relationships on later on quality of romantic relationships can be found when investigating the parenting style used on a child. According to theory of attachment, an insecure relationship with both parents could lead to bad regulation of emotion and thus a lower ability to control temper (Sheffield et.al, 2007). The quality of the parent attachment bond can be promoted or obstruct the optimal emotions regulations through more or less suitable strategies of emotion regulation.

Therefore, it is important to comprehend the relationship between parent-child attachment and its influence on romantic relationships because this shows there is many parents can do to influence the well-being of their children in future relationships. Parents can become aware of the degree of influence their relationship with their children has and how it affects their children. Therefore, they could make a proactive determination to improve the quality of their relationship, so in the future, their children can partake in healthy relationships.

One of the implications of this study is that the results of this study cannot be generalized to the entire population considering researcher was using convenience sampling as sampling method. Besides that, small sample size might be one of the reasons that affect the significant relationship between parent attachment and romantic relationship of the young adults. Besides that, another implication of the present research is that all the measures were limited to self-assessment of the respondents which indicate that some of the respondents might not disclose their relationships or feelings towards their parents and, or their partners.

For future studies, a semi-structured interview can be administered to investigate the nature of attachment relationships in adult partnerships. This approach might provide insight into the deeper aspects of the relationship between the parents and the partners.

The study examines the relationships between parent- child attachment on romantic relationship among Young Adults in Malaysia. Previous studies have argued on the relationship between Parent-Child attachment and romantic relationship and some past studies has also supported the fact that attachment between children and their parents will affect the romantic relationships of the children when they reached late adolescents which are as young adults. Based on the overall result, it is concluded that there is a positive moderate significant relationship between Parent- Child Attachment on Romantic Relationship. 


\section{References}

1. Adamczyk, K., \& Segrin, C. (2016). The mediating role of romantic desolation and dating anxiety in the association between interpersonal competence and life satisfaction among polish young adults. Journal of adult development, 23(1), 1-10. https://doi.org/10.1007/s10804-015-9216-3.

2. Ainsworth, M.D.S. (1978). The bowlby-ainsworth attachment theory. Behavioral and brain sciences, 1(3), 436-438. https://doi.org/10.1017/s0140525x00075828

3. Ainsworth, M.D.S., \& Bell, S.M. (1970). Attachment, exploration, and separation: Illustrated by the behavior of one-year-olds in a strange situation. Child development, 41, 49-67.

4. Allen, J.P., McElhaney, K.B., Land, D.J., Kuperminc, G.P., Moore, C.W., O'Beirne-Kelly, H., \& Kilmer, S.L. (2003). A secure base in adolescence: Markers of attachment security in the mother-adolescent relationship. Child development, 74(1), 292-307. https://doi.org/10.1111/1467-8624.t01-1-00536

5. Armsden, G.C., \& Greenberg, M.T. (1987). The inventory of parent and peer attachment: Individual differences and their relationship to psychological well-being in adolescence. Journal of youth and adolescence, 16(5), 427-454.

6. Ávila, M., Cabral, J., \& Matos, P.M. (2012). Identity in university students: The role of parental and romantic attachment. Journal of adolescence, 35(1), 133-142.

7. Black, K.A., \& Schutte, E.D. (2006). Recollections of being loved: Implications of childhood experiences with parents for young adults' romantic relationships. Journal of Family Issues, 27(10), 1459-1480. https://doi.org/10.1177/0192513x06289647

8. Bowlby, J. (1988). A secure base: Parent-child attachment and healthy human development. New York: Basic Books.

9. Bowlby, J. (1969). Attachment and loss: 1. Attachment.

10. Brown, G.L., McBride, B.A., Shin, N., \& Bost, K.K. (2007). Parenting Predictors of Father-Child Attachment Security: Interactive Effects of Father Involvement and Fathering Quality. Fathering: A Journal of Theory, Research \& Practice about Men as Fathers, 5(3).

11. Chok, N. (2010). Pearson's Versus Spearman's and Kendall's Correlation Coefficient for Continuous Data (Graduate). University of Pittsburgh.

12. Cooke, J., Kochendorfer, L., Stuart-Parrigon, K., Koehn, A., \& Kerns, K. (2019). Parent-child attachment and children's experience and regulation of emotion: A meta-analytic review. Emotion, 19(6), 1103-1126.

13. Connolly, J., \& McIsaac, C. (2011). Romantic relationships in adolescence. In M.K. Underwood, \& L.H. Rosen (Eds.), Social development: Relationships in infancy, childhood, and adolescence, 180203Guilford.

14. Creasey, G., \& Ladd, A. (2004). Negative mood regulation expectancies and conflict behaviors in late adolescent college student romantic relationships: The moderating role of generalized attachment representations. Journal of Research on Adolescence, 14(2), 235-255. https://doi.org/10.1111/j.15327795.2004.01402005.x

15. Department of Statistics Malaysia Official Portal. (2019). https://www.dosm.gov.my/v1/index.php

16. Del Toro, M. (2012). The influence of parent-child attachment on romantic relationships. McNair Scholars Research Journal, 8(1), 5. http://scholarworks.boisestate.edu/mcnair_journal/vol8/iss1/5

17. Dinero, R., Conger, R., Shaver, P., Widaman, K. and Larsen-Rife, D. (2011). Influence of family of origin and adult romantic partners on romantic attachment security. Couple and Family Psychology: Research and Practice, $1(\mathrm{~S}), 16-30$.

18. Dush, C.M.K., \& Amato, P.R. (2005). Consequences of relationship status and quality for subjective wellbeing. Journal of Social and Personal Relationships, 22(5), 607-627.

19. Field, A. (2009). Discovering Statistic Using SPSS (3rd ed). Los Angeles, London, New Delhi, Singapore, Washington DC: SAGE.

20. Fincham, F.D., \& Cui, M. (Eds.). (2011). Romantic relationships in emerging adulthood. 170.

21. Fraley, R.C., Waller, N.G., \& Brennan, K.A. (2000). An item response theory analysis of self-report measures of adult attachment. Journal of personality and social psychology, 78(2), 350- 365.

22. Fraley, R.C., \& Shaver, P.R. (2016). Attachment, loss, and grief: Bowlby's views, new developments, and current controversies. Handbook of attachment: Theory, research, and clinical applications, 3, 4062.

23. Fraley, R.C., \& Roisman, G.I. (2019). The development of adult attachment styles: Four lessons. Current opinion in psychology, 25, 26-30.

24. Ghaemi, F., \& Yazdanpanah, M. (2014). The relationship between socio-economic status and academic achievement in the EFL classroom among Iranian university students. European Journal of English Language and Literature Studies, 2(1), 49-57.

25. Hare, A.L., Miga, E.M., \& Allen, J.P. (2009). Intergenerational transmission of aggression in romantic relationships: the moderating role of attachment security. Journal of family psychology, 23(6), 808-818. 
26. Hazan, C., \& Shaver, P. (1987). Romantic love conceptualized as an attachment process. Journal of personality and social psychology, 52(3), 511-524.

27. Hong, Y.R., \& Park, J.S. (2012). Impact of attachment, temperament and parenting on human development. Korean journal of pediatrics, 55(12), 449. https://doi.org/10.3345/kjp.2012.55.12.449

28. Kochendorfer, L.B., \& Kerns, K.A. (2017). Perceptions of parent-child attachment relationships and friendship qualities: Predictors of romantic relationship involvement and quality in adolescence. Journal of youth and adolescence, 46(5), 1009-1021.

29. Lopez, F.G., Melendez, M.C., \& Rice, K.G. (2000). Parental divorce, parent-child bonds, and adult attachment orientations among college students: A comparison of three racial/ethnic groups. Journal of Counseling Psychology, 47(2), 177. https://doi.org/10.1037/0022-0167.47.2.177

30. Malaysia Kini. (2019). 4,963 cases of domestic violence reported last year. https://www.malaysiakini.com/news/461811

31. Mikulincer, M., \& Shaver, P.R. (2007). Boosting attachment security to promote mental health, prosocial $\begin{array}{llll}\text { values, and inter-group tolerance. Psychological inquiry, 18(3), 156. } & \text { 139- }\end{array}$ https://doi.org/10.1080/10478400701512646

32. Mikulincer, M. (2004). Attachment working models and the sense of trust: An exploration of interaction goals and affect regulation. In HT. Reis \& C.E. Rusbult (Eds.), Close relationships: Key readings. 175191.

33. Millings, A., Walsh, J., Hepper, E., \& O’Brien, M. (2012). Good Partner, Good Parent. Personality and Social Psychology Bulletin, 39(2), 170-180. doi:10.1177/0146167212468333

34. Nosko, A., Tieu, T.T., Lawford, H., \& Pratt, M.W. (2011). How do I love thee? Let me count the ways: Parenting during adolescence, attachment styles, and romantic narratives in emerging adulthood. Developmental Psychology, 47(3), 645-657.

35. Overbeek, G., Vollebergh, W., Engels, R.C., \& Meeus, W. (2003). Parental attachment and romantic relationships: Associations with emotional disturbance during late adolescence. Journal of Counseling Psychology, 50(1), 28-39.

36. Parker, R., Wellings, K., \& Lazarus, J.V. (2009). Sexuality education in Europe: An overview of current policies. Sex Education, 9(3), 227-242.

37. Petrocelli, J.V. (2003). Hierarchical multiple regression in counseling research: Common problems and possible remedies. Measurement and evaluation in counseling and development, 36(1), 9-22. https://doi.org/10.1080/07481756.2003.12069076

38. Roisman, G.I., Booth-LaForce, C., Cauffman, E., Spieker, S., \& NICHD Early Child Care Research Network. (2009). The developmental significance of adolescent romantic relationships: Parent and peer predictors of engagement and quality at age 15. Journal of Youth and Adolescence, 38(10), 1294.

39. Rosenthal, N.L., \& Kobak, R. (2010). Assessing adolescents' attachment hierarchies: Differences across developmental periods and associations with individual adaptation. Journal of research on adolescence, 20(3), 678-706. http://dx.doi.org/10.1111/j.1532-7795.2010.00655.x

40. Sharma, S.R. (2005). Management of School Organisations. Shri Sai Printographers.

41. Morris, A.S., Silk, J.S., Steinberg, L., Myers, S.S., \& Robinson, L.R. (2007). The role of the family context in the development of emotion regulation. Social development, 16(2), 361-388.

42. Twedt, M. (2013). A Comparison of the Attachment with Parents and the Attachment of Romantic Partner. Ph. D. College of Saint Benedict/Saint John's University.

43. Cruz, G.V. (2014). The effect of sex knowledge, parent-child attachment, and family characteristics on intimate relationship satisfaction of Mozambican students. Sexuality \& Culture, 18(1), 1-15.

44. Waters, E., Merrick, S., Treboux, D., Crowell, J., \& Albersheim, L. (2003). Attachment security in infancy and early adulthood: A twenty-year longitudinal study. In M.E. Hertizig \& E.A. Farber (Eds.), Annual progress in child psychiatry and child development: (2000-2001), 63-72.

45. Women's Aid Organisation. (2020). Statistics of Domestic Violence in Malaysia. https://wao.org.my/domestic-violence-statistics/ 